\title{
Nephrotic presentation in hydatid cyst disease with predominant tubulointerstital disease
}

This article was published in the following Dove Press journal: International Journal of Nephrology and Renovascular Disease 23 June 2009

Number of times this article has been viewed

\author{
Feroz Aziz' \\ Tanmay Pandya' \\ Himanshu V Patel' \\ Paladugu Ramakrishna' \\ Kamal R Goplani' \\ Manoj Gumber' \\ Aruna V Vanikar ${ }^{2}$ \\ Kamal Kanodia ${ }^{2}$ \\ Pankaj R Shah' \\ Hargovind L Trivedi' \\ 'Department of Nephrology \\ and Transplantation Medicine; \\ ${ }^{2}$ Department of Pathology, Lab \\ Medicine, Transfusion Services and \\ Immunohematology, G.R. Doshi \\ and K.M. Mehta Institute of Kidney \\ Diseases and Research Centre \\ (IKDRC), Ahmedabad, Gujarat, India
}

Correspondence: $\mathrm{H}$ L Trivedi Institute of Transplantation Sciences (ITS), Civil Hospital Campus, Asarwa, Ahmedabad 3800 16, Gujarat, India

Tel +9l 7922685700

Fax +9l 7922685454

Email drfero@rediffmail.com
Abstract: Renal involvement, which can rarely occur in echinococcosis, more commonly manifests as hydatid cyst of the kidney. Scattered case reports of nephrotic syndrome secondary to hydatid cyst in the liver or lung have been reported for over two decades. The glomerular picture varied from minimal change lesion to mesangiocapillary glomerulonephritis. We report a case of predominantly tubulointerstitial nephritis with mesangioproliferative glomerulonephritis in a patient with hepatic hydatid cyst which responded to cyst resection alone.

Keywords: echinococcosis, hydatid cyst, kidney, nephrotic syndrome, tubulointerstitial nephritis

\section{Introduction}

Echinococcosis or hydatid disease is caused by larvae of the tapeworm, Echinococcus. Echinococcosis has a worldwide distribution. In cystic echinococcosis, humans are an accidental host and are usually infected after handling an infected dog. The liver and lungs are the most frequently involved organs. Rarely occurrences of primary cysts in kidneys have been reported, with the consequent finding of jellylike hydatid material in the urine. ${ }^{1}$ Few cases of glomerular lesions that presented with nephrotic syndrome associated with hydatid disease have been described. We report a unique case of a female who presented with nephrotic syndrome due to mesangioproliferative glomerulonephritis with acute or chronic tubulointerstitial nephritis with a large hepatic hydatid cyst. Proteinuria was abolished by surgical cyst removal and restored the patient to sustained good health.

\section{Case report}

An 18-year-old female presented with complaints of generalized edema of three months duration in January 2008. She also had loss of appetite, low grade fever, and right-sided upper abdominal pain for the same duration. She did not have any discoloration of urine, joint pain, skin rash, or hair loss. She had no history of allergies, tuberculosis, or hypertension.

On admission to the hospital she had pallor and anasarca with ascites. She was afebrile with normal blood pressure. Her liver was enlarged and extended $4 \mathrm{~cm}$ below the costal margin in midcalvicular line. Liver was firm and tender. No other organomegaly was noted.

Urine was positive for protein on dipstick and contained red cells, pus cells, and proteinaceous casts. She was excreting $3.2 \mathrm{~g}$ of urinary protein in 24 hours. Renal function 
was normal. Her hemoglobin was $9.8 \mathrm{~g} / \mathrm{dL}$ with normochromic, normocytic picture with no evidence of hemolysis. Her complete blood count was normal and autoantibody screen (antinuclear and antineutrophil cytoplasmic) was negative. The complement levels C3 and C4 were normal. The liver function was normal except for that serum albumin level was significantly low with a value of $1.8 \mathrm{~g} / \mathrm{dL}$ and total protein was $4.3 \mathrm{~g} / \mathrm{dL}$. The serum cholesterol level was elevated and was $465 \mathrm{mg} / \mathrm{dL}$.

Chest X-ray revealed a raised right hemidiaphragm. Renal ultrasound showed normal kidneys except for slightly increased echogenecity.Liver ultrasound showed fluid filled cavity of $9.3 \times 8.1 \mathrm{~cm}$ with multiple cysts within it in the left lobe of liver. Ultrasound also revealed mild ascites. Serology for Echinococcus granulosus (IgG/IgM) was positive. Computed tomography (CT) scan of the abdomen showed an $11 \times 10 \times 6 \mathrm{~cm}$ cystic lesion with areas of rim calcification and few small cysts within it in the left lobe of liver which was extending into the lesser sac (Figure 1). Mild ascites were also noted. The above findings confirmed the diagnosis of hydatid disease of liver. The patient was subjected to renal biopsy as it was a nephrotic presentation. Renal biopsy revealed mesangial proliferation with acute on chronic tubulo-interstitial nephritis (Figures 2, 3). Electron microscopy was not done as there was no in-house facility.

Treatment was started with diuretics, albumin infusion, and high protein diet. The patient was also initiated with albendazole $400 \mathrm{mg}$ twice a day. After three weeks of preparation, hepatic cyst resection was done. The laparotomy was uneventful and histopathological evaluation of the resected specimen confirmed the diagnosis of hydatid cyst.

Two weeks after surgery, the serum albumin had only marginal improvement to $2.2 \mathrm{~g} / \mathrm{dL}$ and 24-hour urine protein excretion was $2.5 \mathrm{~g}$. One month after surgery, the 24-hour urine protein excretion decreased to less than $1 \mathrm{~g}$. Two months after surgery, the serum albumin level became $3.6 \mathrm{~g} / \mathrm{dL}$ and 24 -hour urine protein excretion became less than $300 \mathrm{mg}$. Follow-up urine examination and ultrasound was normal for one year after surgery, which confirmed good renal recovery and absence of residual hepatic Echinococcus disease. Albendazole was given for a total of twelve weeks. The patient was never treated with steroids or any other immunosuppressant.

\section{Discussion}

Parasitic infections (ie, Protozoa or helminths) may be responsible for acute or chronic diseases which may result in a variety of renal complications. ${ }^{2}$ These can be a direct consequence of the parasite's life cycle or more often caused by either the host's immune response to infection. Echinococcosis or hydatid disease is caused by larvae of the tapeworm, Echinococcus. The usual life-cycle is between dogs and sheep, with humans infrequently accidental hosts. ${ }^{3}$

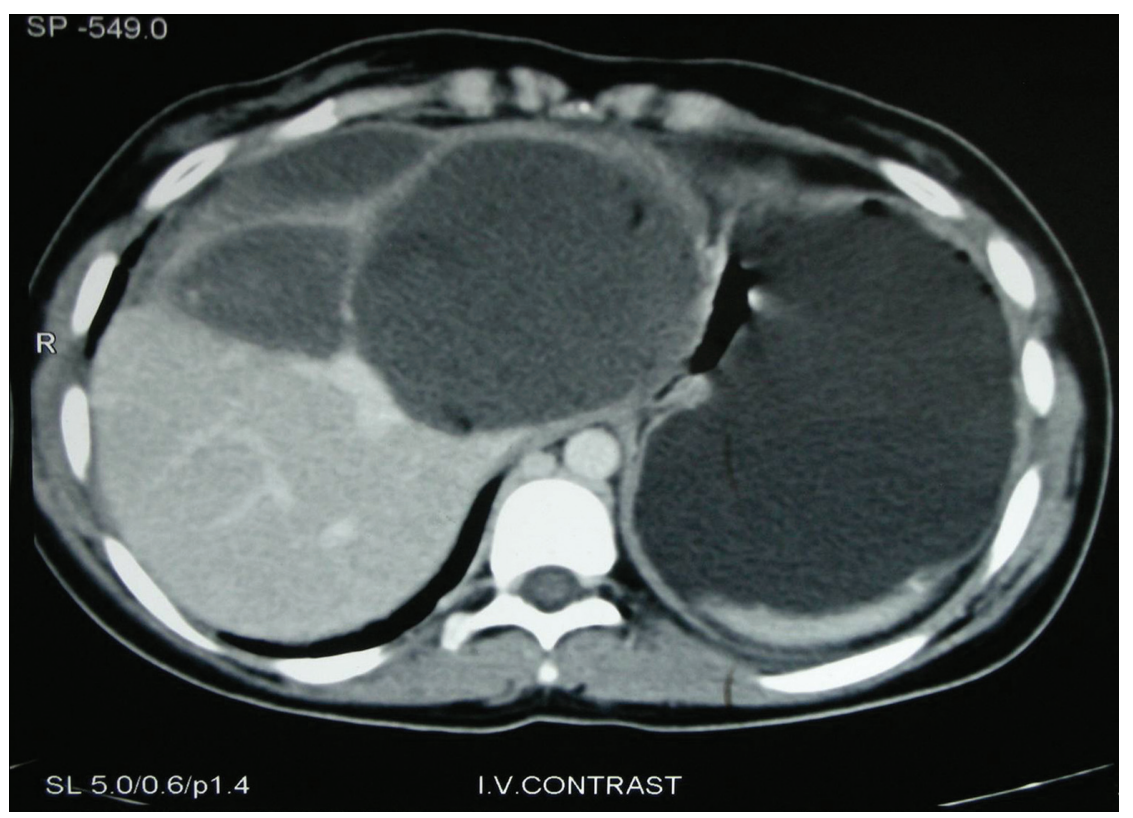

Figure I CT abdomen: II $\times 10 \times 6 \mathrm{~cm}$ cystic lesion with areas of rim calcification and few small cysts within it noted in the left lobe of liver extending into lesser sac. Mild ascites. Suggestive of hydatid disease of liver.

Abbreviation: $\mathrm{CT}$, computed tomography. 


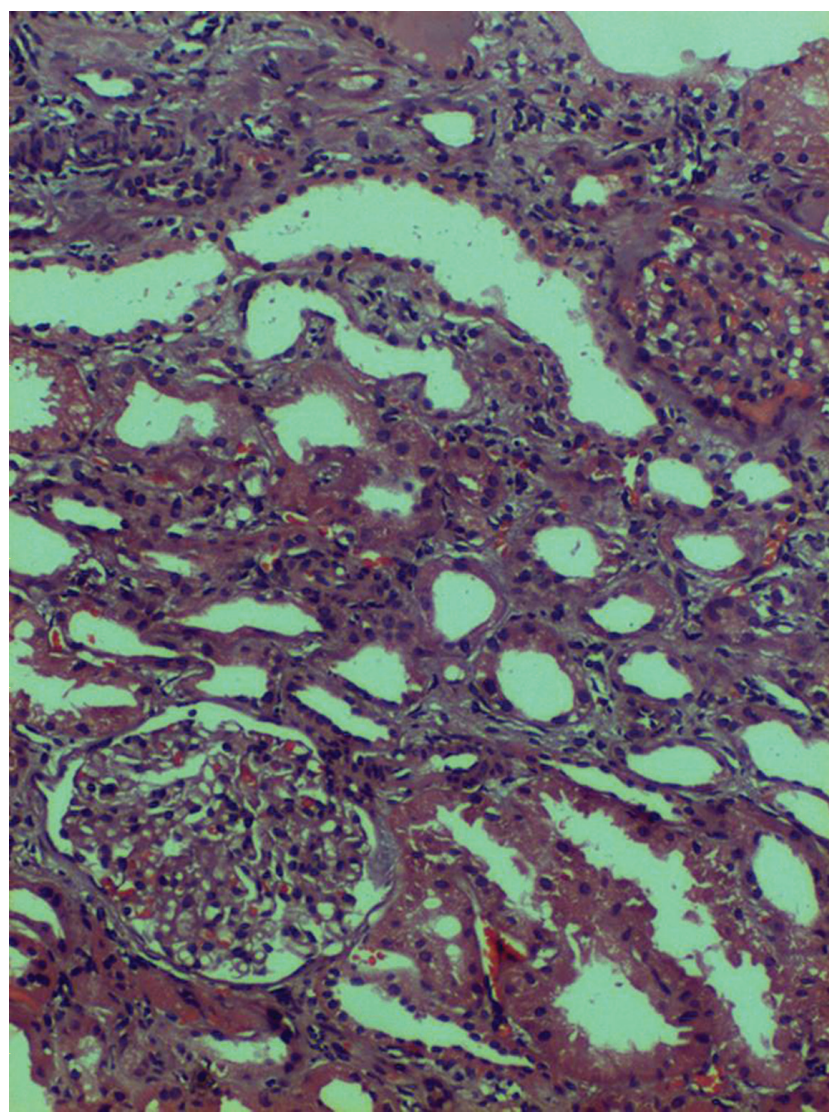

Figure 2 Glomeruli showed moderate mesangial matrix accentuation with hypercellularity. Capillary lumina were open with thickened, wrinkled membranes. Bowman's capillary segmentally thickened and occasionally ruptured. Tubules had moderate degenerative changes. Mild interstitial edema with diffuse mixed leucocytic infiltration noted.

Note: Immunoflouresence showed nonspecific IgM trapping.

The embryos escape from the eggs, penetrate the intestinal mucosa of the human host, and enter the portal circulation. Although most larvae are filtered out by the liver and lungs, some escape to the general circulation to involve other sites such as the kidneys (2\%). The larvae that are not destroyed develop into hydatid cysts. ${ }^{4}$

Different types of kidney involvement were reported with hydatid cyst disease. Most reports of hydatid disease and renal involvement concern development of renal cysts. ${ }^{4}$ A few cases of glomerular lesions that presented with nephrotic syndrome associated with hydatid disease have been described. The histological changes reported have been minimal change lesion and disease, membranous nephropathy, and mesangiocapillary glomerulonephritis., ${ }^{3,5-7}$

Miatello and colleagues ${ }^{8}$ were the first to describe a patient in whom nephrotic syndrome disappeared following the excision of a pulmonary hydatid cyst. Subsequently in 1981, Vialtel and colleagues ${ }^{5}$ and Sánchez Ibarrola and colleagues ${ }^{6}$ reported a case each of membranous

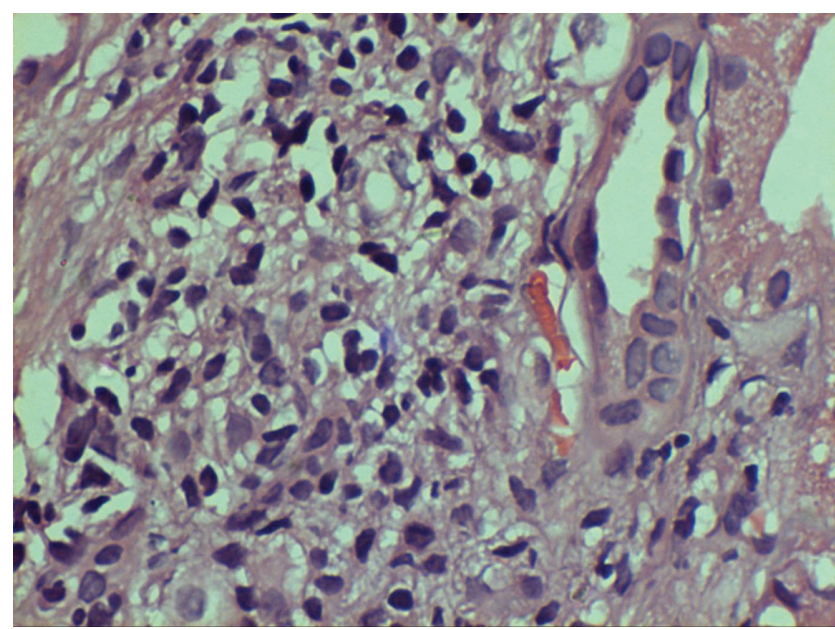

Figure 3 Acute on chronic tubulo-interstitial nephritis with mesangioproliferative glomerulonephritis.

Note: immunoflouresence showed nonspecific IgM trapping.

nephropathy secondary to hydatid cyst. Both the cases had resolved by surgical resection of the cyst. In 1996, Covic and colleagues ${ }^{3}$ reported a 67 -year-old patient who had developed mesangiocapillary glomerulonephritis secondary to hepatic hydatid disease who responded to the removal of the echinococcal cysts. Gelman and colleagues ${ }^{7}$ also described a 63-year-old man with minimal change glomerulonephritis. Oner and colleagues ${ }^{9}$ reported a case of post-infectious glomerulonephritis associated with hepatic hydatid disease. des Grottes and colleagues ${ }^{10}$ reported a case with secondary immunoglobulin A (IgA) glomerulonephritis. Kaaroud and colleagues ${ }^{11}$ reported a case where renal amylodosis had a recovery after cyst resection and colichicine treatment.

Most cases of glomerular lesions associated with hydatid disease are reported to be reversible by treating the infection. ${ }^{3,5}$ Moreover, Viatel and colleagues ${ }^{5}$ eluted echinococcal antigens and antibodies to these antigens from renal tissue of their patient; supporting an immune-complex-mediated pathogenesis. The naturally existing model of E. granulosusassociated membranoproliferative glomerulonephritis in sheep might help to unravel the mechanisms involved in this disease, ${ }^{12}$ but follow-up of these studies has not been reported. Edelweiss and colleagues ${ }^{12,13}$ had been successful in showing echinococcal antigen and corresponding antibody in the glomeruli by immunoperoxidase studies. Continual antigen presentation as an E. granulosus antigen may cause long-lasting antibody response that causes antigen-antibody deposition in the glomerular basement membrane. ${ }^{14}$ Although we were unable to demonstrate the E. granulosus antigens in the basement membrane of our patient, the aforementioned 
clinical course favors an association between this infectious agent and the nephrotic syndrome of this patient.

\section{Disclosure}

The authors report no conflicts of interest in this work.

\section{References}

1. Musacchio E, Mitchell N. Primary renal echinococcosis: a case report. Am J Trop Med Hyg. 1966;67(2):880-883.

2. Thuraisingham R, Adu D. Renal disease in the tropics. In: Cook G, editor. Manson's Tropical Diseases. London: WB Saunders; 1996. p. $174-192$.

3. Covic A, Mititiuc I, Caruntu L, Goldsmith DJ. A Reversible neprotic syndrome due to mesangiocapillary glomerulonephritis secondary to hepatic hydatid disease. Nephrol Dial Transplant. 1996;11:2074-2076.

4. van Velthuysen ML, Florquin S. Glomerulopathy associated with parasitic infections. Clin Microbiol Rev. 2000;13(1):55-66.

5. Vialtel P, Chenais F, Desgeorges P, Couderc P, Micouin C, Cordonnier D. Membranous nephropathy associated with hydatid disease. N Engl J Med. 1981;304(10):610-611.

6. Sánchez Ibarrola A, Sobrini B, Guisantes J, et al. Membranous glomerulonephritis secondary to hydatic disease. Am J Med. 1981;70(2):311-315.
7. Gelman R, Brook G, Green J, Ben-Itzhak O, Nakhoul F. Minimal change glomerulonephritis associated with hydatid disease. Clin Nephrol. 2000;53(2):152-155.

8. Miatello VR, Zanetti NL. [Disappearance of a nephrotic syndrome following the excision of a pulmonary hydatic cyst]. Medicina (B Aires). 1974;34(5):532-538.

9. Oner A, Demercin G, Akhan O, Oner K. Renal hydatid cyst detected in a child during the course of acute poststreptococcal glomerulonephritis. Nephron. 1995;69(2):193-194.

10. des Grottes JM, Oana-Cahoolessur M, Neve P, Vanhaeverbeek M. [Mediastinal and pulmonary hydatidosis, bronchocentric granulomatosis and IgA glomerulonephritis]. Acta Clin Belg. 1993;48(5): 338-343.

11. Kaaroud H, Ben Moussa F, Béji S, Kheder A, Ben Maïz H. [Renal amyloidosis secondary to hydatid cyst of the liver. Clinical remission after surgical excision]. Nephrologie. 2002;23(5):213-217.

12. Albano Edelweiss MI, Lizardo-Daudt HM. Naturally existing model of glomerulonephritis mediated by immune complexes associated with hydatidosis in sheep. Nephron. 1991;57(2):253-254.

13. Edelweiss MI, Daudt HM, Goldstein HF, Garcia C. [Hepatic hydatidosis with glomerular involvement: report of a case]. Rev Assoc Med Bras. 1992;38(1):31-32.

14. Wardle EN. Minimal change nephrosis and allergy. Nephron. 1996; 74(2):422-423.

\section{Publish your work in this journal}

The International Journal of Nephrology and Renovascular Disease is an international, peer-reviewed open-access journal focusing on the pathophysiology of the kidney and vascular supply. Epidemiology, screening, diagnosis, and treatment interventions are covered as well as basic science, biochemical and immunological studies. The journal welcomes original

Submit your manuscript here: http://www.dovepress.com/international-journal-of-nephrology-and-renovascular-disease-journal research, clinical studies, reviews \& evaluations, expert opinion and commentary, case reports and extended reports. The manuscript management system is completely online and includes a very quick and fair peerreview system, which is all easy to use. Visit http://www.dovepress.com/ testimonials.php to read real quotes from published authors. 